\title{
A low number of tumor-infiltrating FOXP3-positive cells during primary systemic chemotherapy correlates with favorable anti-tumor response in patients with breast cancer
}

\author{
TOMOYUKI ARUGA ${ }^{1}$, EIJI SUZUKI ${ }^{1}$, SHIGEHIRA SAJI $^{1}$, SHIN-ICHIROU HORIGUCHI $^{2}$, \\ KAZUMI HORIGUCHI ${ }^{1}$, SUSUMU SEKINE ${ }^{1}$, DAI KITAGAWA ${ }^{1}$, NOBUAKI FUNATA ${ }^{2}$, \\ MASAKAZU TOI ${ }^{3}$, KENICHI SUGIHARA ${ }^{4}$ and KATSUMASA KUROI ${ }^{1}$
}

Departments of ${ }^{1}$ Surgery and ${ }^{2}$ Pathology, Tokyo Metropolitan Cancer and Infectious Diseases Center Komagome Hospital, 3-18-22 Honkomagome, Bunkyo-ku, Tokyo 113-8677; ${ }^{3}$ Department of Surgery (Breast Surgery), Graduate School of Faculty of Medicine, Kyoto University, 54 Shogoin-Kawara-cho, Sakyo-ku, Kyoto 606-8507; ${ }^{4}$ Department of Surgical Oncology, Graduate School of Medicine, Tokyo Medical and Dental University, 1-5-45, Yushima, Bunkyo-ku, Tokyo 113-8519, Japan

Received January 29, 2009; Accepted April 27, 2009

DOI: $10.3892 /$ or_00000434

\begin{abstract}
Cancer cells induce proliferation and local accumulation of immunosuppressive cells, such as FOXP3-positive cells known as regulatory $\mathrm{T}$ cells (Tregs), leading to tumorinduced immune tolerance. Although cancer chemotherapy is usually considered immunosuppressive, some chemotherapeutic agents activate an anticancer immune response. Therefore, we postulated that the number of tumor-infiltrating FOXP3-positive cells during primary systemic chemotherapy (PSC) correlates with therapeutic outcomes in patients with breast cancer. Between September 2000 and January 2005, we examined 93 patients with breast cancer diagnosed by core-needle biopsy and treated with PSC. Core-needle biopsy (CNB) and surgical resected specimens were stained with a FOXP3 mouse monoclonal antibody to compare the numbers of FOXP3-positive cells in the tumors before and after PSC. A median cut-off value of $>16.3 /$ high power field (HPF) and $>6.6 / \mathrm{HPF}$ defined high numbers of Tregs in CNB and in surgical specimens, respectively. We then assigned the patients into 4 groups $(\mathrm{HH}$, high number of FOXP3-positive cells in both CNB and surgical specimen; LL, low number in both specimens; HL, high in CNB and low in the surgical specimen; LH, low in CNB and high in surgical specimen). Lymph vessel invasion-positive, clinically non-responder and
\end{abstract}

Correspondence to: Dr T. Aruga, Department of Surgery, Tokyo Metropolitan Cancer and Infectious Diseases Center Komagome Hospital, 3-18-22 Honkomagome, Bunkyo-ku, Tokyo 113-8677, Japan

E-mail: aruga@cick.jp

Key words: regulatory T cells, FOXP3, breast carcinoma, primary systemic chemotherapy
ER-negative tumors contained significantly more FOXP3positive cells after PSC $(\mathrm{p}=0.04, \mathrm{p}=0.03$ and $\mathrm{p}=0.04$, respectively). Prognosis was better among patients with low numbers than high numbers of FOXP3-positive cells both in $\mathrm{CNB}$ and in surgically resected specimens. In multivariate analysis, LL group demonstrated significantly better recurrence-free survival with risk ratio of 5.81 (95\%CI, 1.09107.5; $\mathrm{p}=0.04$ ) rather than that of non-LL group (LH, HL and $\mathrm{HH})$. These findings suggest that the number of FOXP3positive cells identified during PSC represents a promising predictive factor that might also be an important therapeutic target for breast cancer.

\section{Introduction}

Primary systemic treatment (PST) before surgery has become a standard therapeutic strategy for operable breast cancer. Primary systemic chemotherapy (PSC) is as effective as adjuvant systemic chemotherapy, and it also has several theoretical advantages. Firstly, full-dose chemotherapy can be administered before any potential debilitation from surgery that might increase the likelihood of non-compliance with chemotherapy at a time when micrometastases are likely to be at their smallest. Second, it permits radiological and pathological assessment of the effect of a regimen that might guide the selection of postoperative chemotherapy. Thirdly, it can reduce tumor burden and increase the likelihood of breast-conserving surgery with negative margins.

Systemic chemotherapy is usually considered to be immunosuppressive, considering its toxicity towards hematopoietic cells. However, some chemotherapeutic agents can activate an anticancer immune response by depleting immunosuppressive cells such as $\mathrm{CD} 4^{+} \mathrm{CD} 25^{+}$regulatory $\mathrm{T}$ cells and myeloid-derived suppressor cells (1-3). The X chromosomeencoded forkhead transcription factor FOXP3 has been established as a key transcription factor for $\mathrm{CD}^{+} \mathrm{CD}_{25} 5^{+}$regulatory $\mathrm{T}$ cells (Tregs) (4) that play a vital role in preventing autoimmunity and pathology inflicted by uncontrolled immune 
responses to infection. However, increasing evidence indicates that Tregs also play an important role in immune evasion mechanisms used by cancers (5-13). Tumors actively recruit and induce Tregs to block innate and adaptive immune priming, effector function and memory response, which can result in a favorable environment for cancer progression.

Therefore, we postulated that a low number of tumorinfiltrating FOXP3-positive cells during PSC constitutes an unfavorable environment for breast cancer and that it correlates with the antitumor response in patients with breast cancer. The present study examines correlations between the number of tumor-infiltrating FOXP3-positive cells during PSC and therapeutic effects (tumor response, RFS and OS) in patients with breast cancer.

\section{Materials and methods}

Patients and tissue sampling. Ninety-three patients who underwent primary systemic chemotherapy (PSC) followed by definitive surgery during September 2000 and January 2005 at Tokyo Metropolitan Cancer and Infectious Diseases Center Komagome Hospital, Tokyo, Japan were consecutively enrolled in this study. Informed consent was obtained from all patients before PSC and institutional review board of Komagome hospital approved.

All patients were diagnosed with invasive breast carcinoma by needle biopsy; 3 were excluded because excisional biopsy was performed before PSC and 3 others in pathological complete remission were also excluded because of difficulties associated with identifying 'tumor-infiltrating' Tregs. Thus, 87 of the originally enrolled patients were evaluated.

Clinical and pathological response evaluation. Clinical responses to PSC were evaluated by ultrasonography based on the Response Evaluation Criteria in Solid Tumors (RECIST).

We applied the Japanese pathological response criteria defined as follows: grade 0 , no chemotherapeutic change in remnant cancer cells; grade $1 \mathrm{a}, 0-1 / 3$ of remnant cancer cells in degeneration or necrosis; grade $1 \mathrm{~b}, 1 / 3-2 / 3$; grade $2,>2 / 3$; grade 3 , no viable cancer cells in duct and stroma $(14,15)$.

Immunohistochemical staining and quantification of FOXP3 positive cell. Thick paraffin sections ( $4 \mu \mathrm{m})$ mounted on silane-coated glass slides were dewaxed in xylene, rehydrated through a graded ethanol series and then incubated in $1 \mathrm{mM}$ EDTA at $98^{\circ} \mathrm{C}$ for $40 \mathrm{~min}$, followed by $0.3 \%$ hydrogen peroxide in methanol for 15 min to inhibit endogenous peroxidase activity, primary FOXP3 mouse monoclonal antibody (clone: mAbcam22509) diluted 1:50 in PBS for $30 \mathrm{~min}$ at room temperature and the reagent provided with the Elite ABC kit (Vectastain, Vector Laboratories, Burlingame, CA, USA). Cells were visualized using the chromogen diaminobenzidine and counterstained with Meyer's hematoxylin.

Average numbers of FOXP3-positive cells within the neoplastic epithelium and immediately adjacent stroma were determined from scores in 3 and 5 random high-power fields (HPF; $x 40$ objective and x10 eyepiece, CFWN 10x) in CNB and surgical specimens, respectively. A median cut-off value

Table I. Patient background $(\mathrm{n}=87)$.

Age (years)

Follow-up period

Tumor size

before PSC

PSC regimen
23-69 (median, 51)

5.3-89.1 months (median, 46.3)

$0.9-13.5 \mathrm{~cm}$ (median, 4.7)

Anthracycline only 17 (FEC, 500$100-500 / \mathrm{m}^{2}$ or EC, $\left.90-600 / \mathrm{m}^{2} \mathrm{q} 3 \mathrm{w}\right)$ Taxane containing 70 (Docetaxel $75 / \mathrm{m}^{2} \mathrm{q} 3 \mathrm{w}$ or Paclitaxel $80 / \mathrm{m}^{2} \mathrm{qw}$ )

Clinical

response ${ }^{a}$

CR 3

PR 57

SD $\quad 22$

PD 3

Unknouwn 2

Pathological

response ${ }^{\mathrm{b}}$

Grade $0 \quad 15$

Grade 1a $\quad 37$

Grade $1 \mathrm{~b} \quad 17$

Grade 2

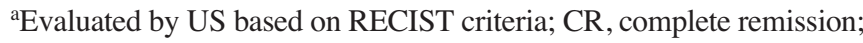
$\mathrm{PR}$, partial response; SD, stable disease; $\mathrm{PD}$, progressive disease. bPathological response defined as: grade 0 , no chemotherapeutic change in remnant cancer cells; grade $1 \mathrm{a}, 0-1 / 3$ of remnant cancer cells in degeneration or necrosis; grade $1 \mathrm{~b}, 1 / 3-2 / 3$; grade $2,>2 / 3$; grade 3 , no viable cancer cells in duct and stroma.

of $>16.3$ and $>6.6 / \mathrm{HPF}$ defined patients with high numbers of Tregs in CNB and surgical specimens, respectively.

ER, PgR and HER2 status. For estrogen receptor (ER), progesterone receptor (PgR), and human epidermal growth factor receptor-2 (HER2) evaluation, immunohistochemical staining were performed using anti-ER mouse monoclonal antibody (clone1D5; Dako), anti-PgR mouse monoclonal antibody (clone PgR636; Dako) and a HercepTest kit (Dako), respectively. Hormone receptor status was evaluated as the percentage of positive nuclear staining among cancer cells, and the cut-off value was set to $10 \%$. HER 2 scoring was carried out according to the standard Hercep Test Guidelines.

Statistical analysis. The association between number of Tregs and clinicopathological/biological features was examined using the $\chi^{2}$ test and Fisher's exact probability test. Correlations between the numbers of FOXP3 and RFS and OS were determined using the log-rank and Wilcoxon tests. Associations between changes in numbers of FOXP3-positive cells during PSC and prognosis were assessed using the Cox proportional hazard model. 

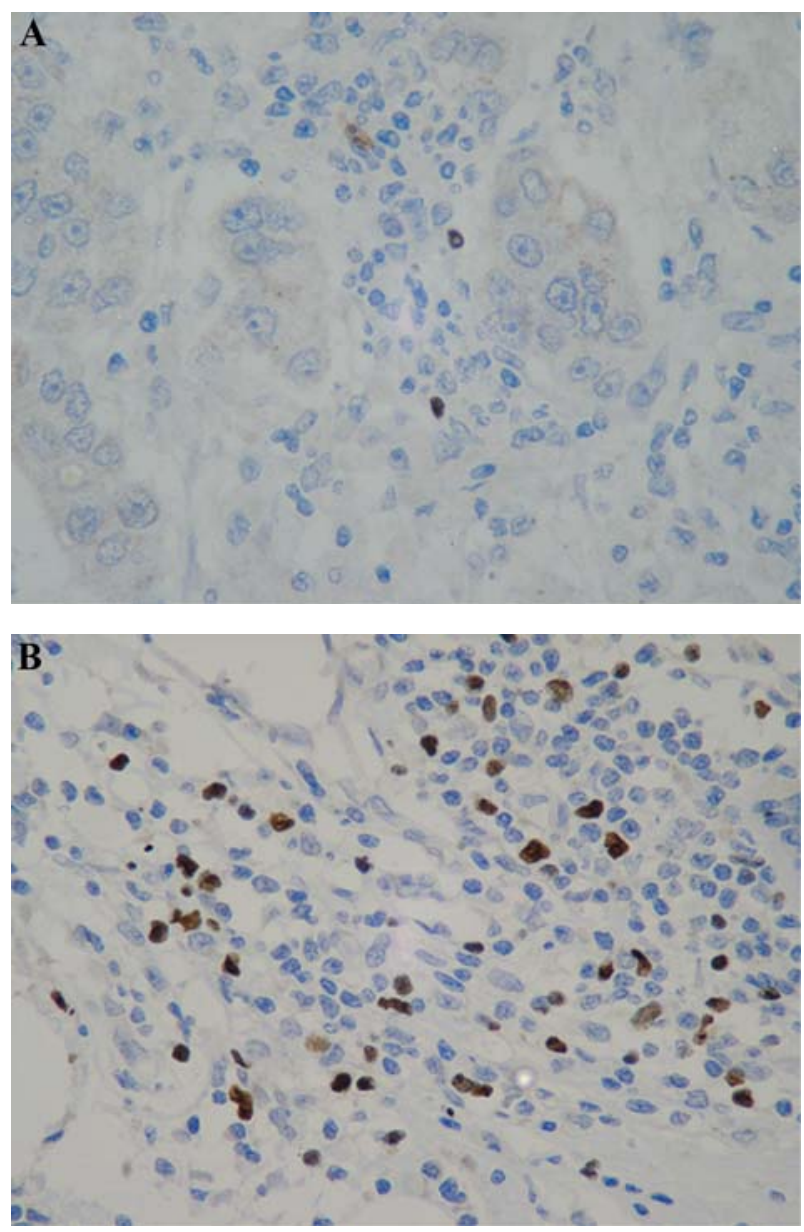

Figure 1. Representative immunohistochemical staining with FOXP3 antibody. (A) Low number FOXP3-positive cells; (B) high number FOXP3positive cells.

The data were analyzed using the JMP(r) version 7 software package (SAS institute Inc, USA). A p-value $<0.05$ was considered statistically significant.

\section{Results}

Patient background. The median age of the enrolled patients was 51 years (range, 23-69 years), median tumor size before PSC was $4.7 \mathrm{~cm}$ (range, 0.9-13.5 cm) and median follow-up period was 46.3 months (range, 5.3-89.1 months). All patients received a regimen containing anthracycline (FEC or EC) and 70 patients (80.5\%) received a sequential regimen containing taxane. None of the patients were administered with trastsuzumab or hormonal therapy before surgery. Sentinel lymph node biopsy was conducted on 32 patients before starting PSC and 8 patients did not undergo axillary lymph node dissection after PSC. Fifty-seven patients achieved partial response (PR) and 22 remained stable disease (SD). Three patients each were in clinically complete remission (CR) and progressive disease (PD), respectively.

Fifteen patients were diagnosed with a grade 0 pathological response, and 37, 17 and 18 patients were diagnosed with grades $1 \mathrm{a}, 1 \mathrm{~b}$ and 2 , respectively. Three patients achieved complete pathological remission and were excluded from analysis (Table I).
Table II. Correlation between number of tumor-infiltrating Tregs and clinicopathological features of 87 CNB specimens before PSC.

\begin{tabular}{|c|c|c|}
\hline Variable & $\begin{array}{c}\text { FOXP3 }<16.3 \\
\text { Low }(n=43)\end{array}$ & $\begin{array}{c}\text { FOXP3 } \geq 16.3 \\
\text { High }(n=44)\end{array}$ \\
\hline
\end{tabular}

\begin{tabular}{lrrr}
\hline $\begin{array}{l}\text { Age (years) } \\
<50\end{array}$ & 20 & 19 & 0.75 \\
$\geq 50$ & 23 & 25 & \\
ER status & & & \\
$\quad$ Negative & 4 & 18 & 0.007 \\
Positive & 39 & 26 & \\
PgR status & & & \\
Negative & 12 & 29 & 0.004 \\
Positive & 31 & 15 & \\
HER2 status & & & \\
$0,1,2$ & 39 & 37 & $0.45^{\mathrm{a}}$ \\
3 & 4 & 6 & \\
Unknown & 0 & 1 & \\
Clinical response & & & \\
CR + PR & 30 & 30 & \\
SD + PD & 12 & 13 & \\
Unknown & 1 & 1 & \\
Pathological & & & \\
response & & 36 & \\
Grade 0, 1 & 33 & & \\
Grade 2 & 10 & &
\end{tabular}

Recurrence-free

survival

Worse $\quad 0.285^{\mathrm{b}}$

Overall survival

Worse $\quad 0.036^{\mathrm{b}}$

$0.092^{\mathrm{c}}$

n, total number of patients; ER, estrogen receptor; PgR, progesterone receptor; HER2, human epidermal growth factor receptor-2; $\mathrm{CR}$, complete remission; $\mathrm{PR}$, partial response; SD, stable disease; $\mathrm{PD}$, progressive disease. ${ }^{\mathrm{a}}$ Fisher's exact probability test; ${ }^{\mathrm{b}} \mathrm{log}$-rank test; ${ }^{\mathrm{c} W i l c o x o n}$ test.

FOXP3 expression in CNB specimens and surgical resected specimens. The number of FOXP3-positive cells ranged from 0 to $112 / \mathrm{HPF}$ in CNB specimens (median 16.3) and from 0 to $66.8 / \mathrm{HPF}$ in surgically resected specimens (median 6.6). Patients were classified according to the median number of FOXP3-positive cells (Fig. 1). Negative ER was associated with significantly more FOXP3 infiltrates before and after PSC ( $p=0.007$ and $p=0.04$, respectively) (Tables II and III). The findings were the same among PgR-negative patients before, but not after PSC ( $\mathrm{p}=0.004$ and $\mathrm{p}=0.60$, respectively).

Lymph vessel invasion was prominent in the group with a high number of FOXP3 infiltrates $(\mathrm{p}=0.04)$ (Table III). 
Table III. Correlation between number of tumor-infiltrating Tregs and clinicopathological features of 87 specimens resected after PSC.

\begin{tabular}{lll}
\hline Variable & FOXP3 $<6.6$ & FOXP3 $\geq 6.6 \quad$ P-value \\
& Low $(n=43)$ & High $(n=44)$
\end{tabular}

Age (years)

$<50$

$\geq 50$

20

23

19

PSC regimen

Anthracycline only

$\begin{array}{rr}6 & 12 \\ 37 & 32\end{array}$

Taxane included

Nodal status

Negative

Ax not performed

7

Remnant

tumor size $(\mathrm{cm})$

$\leq 2$

$>2$

27

16

23

Lymph vessel invasion

Negative

Positive

$$
26
$$

17

ER status

Negative

Positive

9

18

26

PgR status

Negative

Positive

$$
27
$$

16

30

14

HER2 status

$$
\begin{aligned}
& 0,1,2 \\
& 3
\end{aligned}
$$

Unknown

32

5

Clinical response

$$
\begin{aligned}
& \mathrm{CR}+\mathrm{PR} \\
& \mathrm{SD}+\mathrm{PD}
\end{aligned}
$$

Unknown

33
9
1

27

1

Pathological

response

Grade 0,1

Grade 2

Recurrence-free survival

\begin{tabular}{lll} 
& Worse & $0.031^{\mathrm{b}}$ \\
& & $0.028^{\mathrm{c}}$ \\
Overall survival & Worse & $0.060^{\mathrm{b}}$ \\
& & $0.142^{\mathrm{c}}$ \\
\hline
\end{tabular}

$\mathrm{n}$, total number of patients; PSC, primary systemic chemotherapy; ER, estrogen receptor; PgR, progesterone receptor; HER2, human epidermal growth factor receptor-2; CR, complete remission; $\mathrm{PR}$, partial response; SD, stable disease; $\mathrm{PD}$, progressive disease.

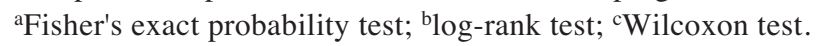

A

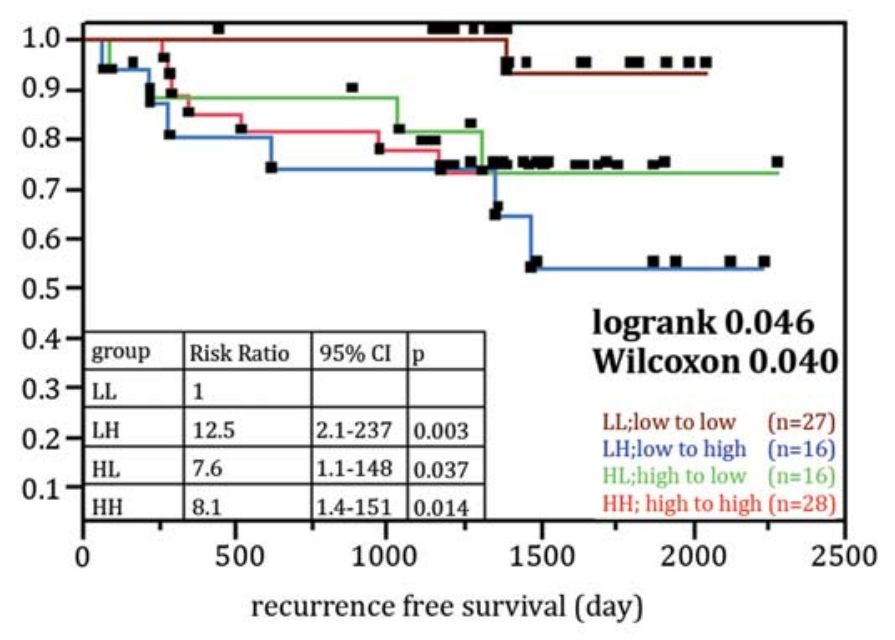

B

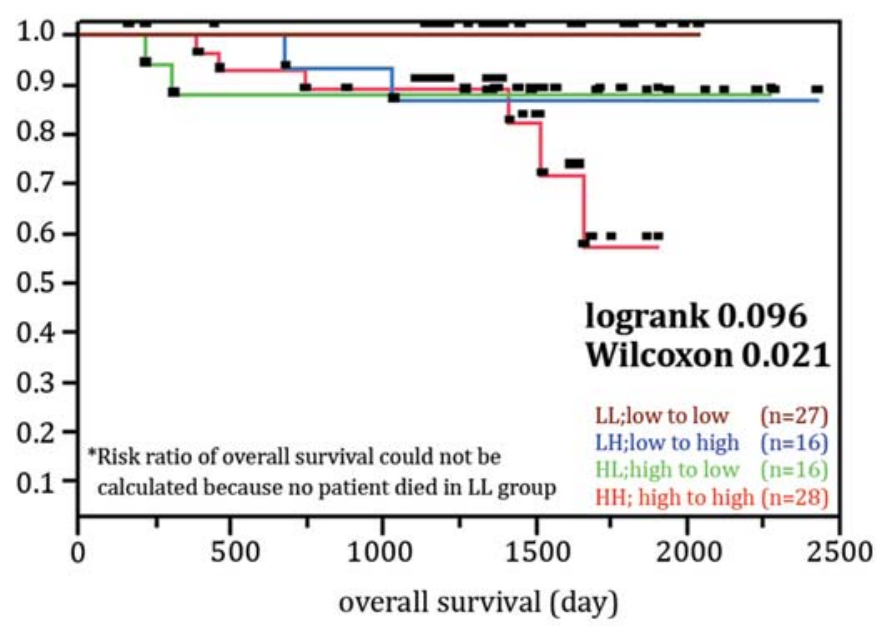

Figure 2. Changes in numbers of FOXP3-positive cells before and after chemotherapy. (A) Recurrence-free survival; (B) overall survival; $\mathrm{HH}$, high number of FOXP3-positive cells in both CNB and surgical specimens; LL, low numbers in both specimens; HL, high number in CNB and low number in surgical specimen; LH, low number in $\mathrm{CNB}$ and high number in surgical specimen.

However, nodal status and the number of FOXP3-positive cells $(\mathrm{p}=0.70)$ did not significantly differ. Importantly, a low number of Tregs in tumors after PSC correlated with clinical response $(C R+P R)(p=0.03)$, although numbers of Tregs did not correlate with pathological response $(\mathrm{p}=0.27)$. Numbers of Tregs in tumors before PSC did not have any predictive impact on clinical and pathological response (Tables II and III). The trend of recurrence-free and overall survival in lowFOXP3 patients evaluated either by CNB or surgical specimens was clearly favorable (Tables II and III).

We also assigned all patients into 4 groups according to the numbers of FOXP3-positive cells in both CNB and surgical specimen: high numbers in both $(\mathrm{HH} ; \mathrm{n}=28)$, low numbers in both ( $\mathrm{LL} ; \mathrm{n}=27)$; high in $\mathrm{CNB}$ and low in surgical specimen (HL; $n=16)$; and low in CNB and high in surgical specimen ( $\mathrm{LH} ; \mathrm{n}=16)$. Prognosis was significantly better in the LL group (Fig. 2). In multivariate analysis, LL group 
Table IV. Multivariate analysis for RFS and OS.

\begin{tabular}{|c|c|c|c|c|c|c|}
\hline \multirow[b]{2}{*}{ Variable } & \multicolumn{3}{|c|}{ RFS } & \multicolumn{3}{|c|}{ OS } \\
\hline & Risk ratio & $95 \% \mathrm{CI}$ & P-value & Risk ratio & $95 \% \mathrm{CI}$ & P-value \\
\hline ER & 3.10 & $1.09-8.61$ & 0.03 & 36.3 & $5.26-776.3$ & $<0.0001$ \\
\hline \multicolumn{7}{|l|}{ FOXP3 } \\
\hline (LL vs. others) & 5.81 & $1.09-107.5$ & 0.04 & ${ }^{\mathrm{a}} 1$ & & 0.32 \\
\hline Nodal status & 1.48 & $0.51-4.71$ & 0.48 & 12.1 & $1.40-299.2$ & 0.02 \\
\hline Age & 1.43 & $0.54-89$ & 0.47 & 7.4 & $1.28-52.0$ & 0.02 \\
\hline
\end{tabular}

${ }^{\mathrm{a}} 1$, risk ratio of overall survival could not be calculated because no patient died in LL group.

demonstrated significantly better recurrence-free survival with risk ratio of $5.81(95 \% \mathrm{CI}, 1.09$ to $107.5 ; \mathrm{p}=0.04)$ rather than that of non-LL group, however, no significant correlation was found in overall survival (Table IV).

\section{Discussion}

FOXP3 is a specific marker for regulatory $\mathrm{T}$ cells (Tregs), which comprise a distinct group of $\mathrm{T}$ lymphocytes with immunosuppressive properties that normally serve to prevent harmful autoimmune responses. However, Tregs can also interfere with beneficial immune responses in humans, such as anti-tumor immunity. FOXP3-positive Tregs are associated with tumor genesis and progression in lung (16), colon (17), melanoma (18), gastric (19), hepatic (20), and pancreatic (21) carcinoma, lymphoma (22) and sarcoma (23). High levels of FOXP3 mRNA expression or high numbers of FOXP3positive cells are associated with unfavorable tumor features and a poor prognosis among patients with breast cancer (24-28).

An appropriate cut-off value must be established before the numbers of FOXP3-positive cells in tumor cells can be clinically applied. Our study showed that high numbers, defined as median cut-off values of 16.3 and 6.6 cells/HPF in $\mathrm{CNB}$ and in surgical resected specimens, respectively, are associated with aggressive tumor features and poor prognosis. Bates et al (28) reported that a high number of FOXP3 cells is associated with unfavorable nodal status, tumor grade, ER status, HER2 status and relapse-free survival with a median cut-off of 15 cells $/ \mathrm{mm}$ diameter invasive tumor cores (approximately 3 cells/HPF). Bohling et al (27) reported that the average number of FOXP3-positive cells/HPF in a group with good clinical feature ranges from 15 to 20/HPF. Although optimization of the cut-off value for clinical use is necessary, these data indicate that the appropriate cut-off to differentiate high and low numbers of FOXP3-positive cells in tumors might be in the range 3-20. Interestingly, we found that the median cut-off value for surgical specimens after PSC was decreased to 6.6/HPF. This might have a detrimental effect on FOXP3-positive Tregs in patients undergoing chemotherapy and could be another important factor for optimizing the cut-off value of FOXP3-positive cell number using tumor specimens after PSC.
Although one possible prognostic factor is pCR after PSC (29), few prognostic factors are available for patients with operable breast cancer after PSC. We found here that fewer FOXP3-positive cells before and after PSC indicates a better prognosis and in the multivariate analysis, preserving relatively low number of FOXP3 during PSC (LL group) is significantly associated with a better RFS; therefore, the number of FOXP3-positive cells in the tumors during PSC could become another prognostic factor in the treatment for breast cancer patients with PSC.

Further analysis discovered changes in the number of FOXP3-positive cells in tumors after PSC (Fig. 2). Although we cannot simply show that numbers of FOXP3-positive cells changed after PSC in the LH and HL groups, the prognosis of the LH group was significantly worse than that of the LL group. Furthermore, the risk ratio for overall survival of HL to $\mathrm{HH}$ was 0.57 , and HL seems to indicate a better overall survival than $\mathrm{HH}$, although the p-value did not reach significance (data not shown). Given these findings and the previous experimental reports that control of Tregs augments antitumor immune responses which provide clinical benefits and some chemotherapeutic agents such as cyclophosphamide specifically diminish Tregs $(30,31)$, we speculate that some chemotherapeutic agents could clinically control FOXP3-positive cells and this might be one of the mechanism of chemotherapeutic agents besides its cytotoxic effect for patients with breast cancer. Further studies are required to prove our hypothesis.

In conclusion, numbers of FOXP3-positive Tregs could constitute an important prognostic factor for patients with breast cancer treated with PSC, and FOXP3-positive cells in tumors could be a novel therapeutic target that could improve outcomes for such patients.

\section{References}

1. Ghiringhelli F, Larmonier N, Schmitt E, et al: $\mathrm{CD} 4{ }^{+} \mathrm{CD} 25^{+}$ regulatory $\mathrm{T}$ cells suppress tumor immunity but are sensitive to cyclophosphamide which allows immunotherapy of established tumors to be curative. Eur J Immunol 34: 336-344, 2004.

2. Ghiringhelli F, Menard C, Puig PE, et al: Metronomic cyclophosphamide regimen selectively depletes $\mathrm{CD} 4{ }^{+} \mathrm{CD} 25^{+}$regulatory $\mathrm{T}$ cells and restores $\mathrm{T}$ and $\mathrm{NK}$ effector functions in end stage cancer patients. Cancer Immunol Immunother 56: 641-648, 2007. 
3. Ko HJ, Kim YJ, Kim YS, et al: A combination of chemoimmunotherapies can efficiently break self-tolerance and induce antitumor immunity in a tolerogenic murine tumor model. Cancer Res 67: 7477-7486, 2007.

4. Fontenot JD, Gavin MA and Rudensky AY: Foxp3 programs the development and function of $\mathrm{CD} 4^{+} \mathrm{CD} 25^{+}$regulatory $\mathrm{T}$ cells. Nat Immunol 4: 330-336, 2003.

5. Bach JF: Regulatory T cells under scrutiny. Nat Rev Immunol 3: 189-198, 2003.

6. Curiel TJ, Coukos G, Zou L, et al: Specific recruitment of regulatory $\mathrm{T}$ cells in ovarian carcinoma fosters immune privilege and predicts reduced survival. Nat Med 10: 942-949, 2004.

7. Dieckmann D, Plottner H, Berchtold S, Berger T and Schuler G: Ex vivo isolation and characterization of CD4(+)CD25(+) T cells with regulatory properties from human blood. J Exp Med 193: 1303-1310, 2001.

8. Levings MK, Sangregorio R and Roncarolo MG: Human $\mathrm{cd} 25(+) \mathrm{cd} 4(+) \mathrm{t}$ regulatory cells suppress naive and memory $\mathrm{T}$ cell proliferation and can be expanded in vitro without loss of function. J Exp Med 193(11): 1295-1302, 2001.

9. Ng WF, Duggan PJ, Ponchel F, et al: Human CD4(+)CD25(+) cells: a naturally occurring population of regulatory $\mathrm{T}$ cells. Blood 98: 2736-2744, 2001.

10. Read S and Powrie F: CD4(+) regulatory T cells. Curr Opin Immunol 13: 644-649, 2001.

11. Shevach EM: $\mathrm{CD}^{+}{ }^{+} \mathrm{CD} 25^{+}$suppressor T cells: more questions than answers. Nat Rev Immunol 2: 389-400, 2002.

12. Von Herrath MG and Harrison LC: Antigen-induced regulatory T cells in autoimmunity. Nat Rev Immunol 3: 223-232, 2003.

13. Wood KJ and Sakaguchi S: Regulatory T cells in transplantation tolerance. Nat Rev Immunol 3: 199-210, 2003.

14. The Japanese Breast Cancer Society: Japanese pathological response criteria of breast cancer. 15th edition. General Rules for Clinical and Pathological Recording of Breast Cancer, pp75-76, 2008.

15. Kurosumi M, Akashi-Tanaka S, Akiyama F, et al: Histopathological criteria for assessment of therapeutic response in breast cancer (2007 version). Breast Cancer 15: 5-7, 2008.

16. Petersen RP, Campa MJ, Sperlazza J, et al: Tumor infiltrating Foxp $3^{+}$regulatory $\mathrm{T}$-cells are associated with recurrence in pathologic stage I NSCLC patients. Cancer 107: 2866-2872, 2006.

17. Loddenkemper C, Schernus M, Noutsias M, Stein H, Thiel E and Nagorsen D: In situ analysis of FOXP3 ${ }^{+}$regulatory $\mathrm{T}$ cells in human colorectal cancer. J Transl Med 4: 52, 2006.

18. Mourmouras V, Fimiani M, Rubegni P, et al: Evaluation of tumour-infiltrating $\mathrm{CD}^{+} \mathrm{CD} 25^{+} \mathrm{FOXP} 3^{+}$regulatory $\mathrm{T}$ cells in human cutaneous benign and atypical naevi, melanomas and melanoma metastases. Br J Dermatol 157: 531-539, 2007.

19. Mizukami Y, Kono K, Kawaguchi Y, et al: Localisation pattern of Foxp $3^{+}$regulatory $\mathrm{T}$ cells is associated with clinical behaviour in gastric cancer. Br J Cancer 98: 148-153, 2008.
20. Sasaki A, Tanaka F, Mimori K, et al: Prognostic value of tumorinfiltrating $\mathrm{FOXP3}^{+}$regulatory $\mathrm{T}$ cells in patients with hepatocellular carcinoma. Eur J Surg Oncol 34: 173-179, 2008.

21. Hiraoka N, Onozato K, Kosuge T and Hirohashi S: Prevalence of $\mathrm{FOXP}^{+}$regulatory $\mathrm{T}$ cells increases during the progression of pancreatic ductal adenocarcinoma and its premalignant lesions. Clin Cancer Res 12: 5423-5434, 2006.

22. Tzankov A, Meier C, Hirschmann P, et al: Correlation of high numbers of intratumoral $\mathrm{FOXP}^{+}$regulatory $\mathrm{T}$ cells with improved survival in germinal center-like diffuse large Bcell lymphoma, follicular lymphoma and classical Hodgkin's lymphoma. Haematologica 93: 193-200, 2008.

23. Betts G, Twohig J, Van den Broek M, Sierro S, Godkin A and Gallimore A: The impact of regulatory $\mathrm{T}$ cells on carcinogeninduced sarcogenesis. Br J Cancer 96: 1849-1854, 2007.

24. Gupta S, Joshi K, Wig JD and Arora SK: Intratumoral FOXP3 expression in infiltrating breast carcinoma: its association with clinicopathologic parameters and angiogenesis. Acta Oncol 46: 792-797, 2007.

25. Ladoire S, Arnould L, Apetoh L, et al: Pathologic complete response to neoadjuvant chemotherapy of breast carcinoma is associated with the disappearance of tumor-infiltrating foxp $3^{+}$regulatory $\mathrm{T}$ cells. Clin Cancer Res 14: 2413-2420, 2008.

26. Ohara M, Yamaguchi Y, Matsuura K, Murakami S, Arihiro K and Okada $\mathrm{M}$ : Possible involvement of regulatory $\mathrm{T}$ cells in tumor onset and progression in primary breast cancer. Cancer Immunol Immunother 58: 441-447, 2009.

27. Bohling SD and Allison KH: Immunosuppressive regulatory $\mathrm{T}$ cells are associated with aggressive breast cancer phenotypes: a potential therapeutic target. Mod Pathol 21: 1527-1532, 2008.

28. Bates GJ, Fox SB, Han C, et al: Quantification of regulatory T cells enables the identification of high-risk breast cancer patients and those at risk of late relapse. J Clin Oncol 24: 5373-5380, 2006.

29. Brain E, Garrino C, Misset JL, et al: Long-term prognostic and predictive factors in 107 stage II/III breast cancer patients treated with anthracycline-based neoadjuvant chemotherapy. Br J Cancer 75: 1360-1367, 1997.

30. Hoover SK, Barrett SK, Turk TM, Lee TM and Bear HD: Cyclophosphamide and abrogation of tumor-induced suppressor $\mathrm{T}$ cell activity. Cancer Immunol Immunother 31: 121-127, 1990.

31. North RJ: Cyclophosphamide-facilitated adoptive immunotherapy of an established tumor depends on elimination of tumor-induced suppressor T cells. J Exp Med 155: 1063-1074, 1982. 